\title{
B-Cell CLL/Lymphoma 7 Protein Family Member B
}

National Cancer Institute

\section{Source}

National Cancer Institute. B-Cell CLL/Lymphoma 7 Protein Family Member B. NCI

Thesaurus. Code C157258.

B-cell CLL/lymphoma 7 protein family member B (202 aa, $22 \mathrm{kDa}$ ) is encoded by the human BCL7B gene. This protein plays a role in chromatin remodeling and apoptotic signaling. 